\title{
The Functional Domain of Adenylate Cyclase Associated with Entry into Meiosis in Saccharomyces cerevisiae
}

\author{
ISAO UNO, ${ }^{1 *}$ TAKEHIRO OSHIMA, ${ }^{2}$ AIKO HIRATA, ${ }^{1}$ AND TATSUO ISHIKAWA ${ }^{1}$ \\ Institute of Applied Microbiology, University of Tokyo, Bunkyo-ku, Tokyo $113,{ }^{1}$ and Suntory Bio Pharma Tech Center, \\ Chiyoda-machi, Oura-gun, Gunma 370-05, Japan
}

Received 15 August 1988/Accepted 2 October 1989

\begin{abstract}
Diploid yeast cells that carry a part of the CYR1 gene deficient in a region coding for the $\mathrm{N}$-terminal domain of adenylate cyclase were growth arrested and accumulated unbudded cells after inoculation into complete medium or nitrogen-free medium, but produced many cells which had one or more buds after incubation in sporulation medium. The cells incubated in sporulation medium had abnormal spindles which were free from the spindle pole bodies, larger in size, or frequently distributed in cytoplasm. The levels of cyclic AMP in these cells did not decrease to the wild-type level after transfer to the sporulation medium and remained at a constant level. The results suggest that the $\mathbf{N}$-terminal domain of adenylate cyclase is associated with the regulatory function for sporulation. The environmental signals for sporulation may be transferred to the adenylate cyclase system through a factor that negatively interacts with the $\mathbf{N}$-terminal domain of this enzyme.
\end{abstract}

Cyclic AMP (cAMP) plays an essential role in regulation of the cell cycle of the yeast Saccharomyces cerevisiae $(17$, 18). Growth of cyrl mutants of $S$. cerevisiae, which require cAMP for growth, is arrested at the G1 state of the mitotic cell cycle in the absence of cAMP (15). The structural gene of yeast adenylate cyclase, $C Y R 1$, has been cloned $(1,13)$ and sequenced $(10,14)$. CYRI has a large continuous open reading frame of 6,078 bases, corresponding to a protein of 2,026 amino acids (10). The catalytic domain of yeast adenylate cyclase was found in the 1.3-kilobase $(\mathrm{kb})$ region of the open reading frame of the $C Y R I$ gene coding for the $C$-terminal domain of adenylate cyclase $(10,14)$. The product of the 2.1-kb region of $C Y R I$ coding for the C-terminal domain of adenylate cyclase showed guanine nucleotidedependent adenylate cyclase activity and produced a large amount of cAMP in the presence of the RAS genes, which are highly homologous to mammalian ras genes $(3,4,19,23)$. We have evidence that a small region adjacent to the region encoding the catalytic domain of yeast adenylate cyclase is associated with the regulatory function of the $R A S$ products (26).

Meiosis and sporulation of yeast diploid cells are normally initiated by nutritional limitation, but diploid cells homozygous for the temperature-sensitive cyrl-2 mutation had a unique ability to sporulate even in rich medium, suggesting that this mutation relates to the choice between mitotic and meiotic processes (16). The levels of cAMP decreased and then increased during sporulation in the wild-type diploid cells, but decreased and remained at a low level in the cyrl-2 diploid cells incubated at the restrictive temperature (24). The cyrl-2 diploid cells were able to initiate meiotic division but produced predominantly two-spored asci at the restrictive temperature (24).

To localize the domain of adenylate cyclase accepting the environmental signal for sporulation such as nutritional limitation, we prepared truncated genes and introduced them into diploid yeast cells. The results indicate that the $\mathrm{N}$ terminal domain of adenylate cyclase is involved in the initiation of sporulation.

\footnotetext{
* Corresponding author.
}

\section{MATERIALS AND METHODS}

Yeast strains and plasmids. The $S$. cerevisiae strains used in this study are listed in Table 1 . The first nine strains, which were derived from the same diploid strain, RA1, and interpreted as being nearly isogenic, were used. As isogenicity and genetic background sometimes affect meiosis and sporulation, we made completely isogenic strains as follows. Strain IU4-1B is a MATa derivative of IU-1B made by HO-promoted mating type interconversion with a construction that places the $\mathrm{HO}$ endonuclease gene under the control of the GAL1 promoter (pGAL-HO) (7). We carried out the same experiments with isogenic strains IU4-1B and IU-1B. We obtained essentially the same results with these isogenic strains. Plasmid pCEY710, which carries the complete open reading frame of $C Y R I$ (13), was first cleaved at the $B g l$ II site in the $3^{\prime}$ noncoding region and then cleaved completely with the same enzyme or cleaved partially with $S c a I$. The resulting DNA fragments of expected sizes were isolated (Fig. 1) and inserted at the multicloning sites of pUC18 in order to maintain their correct reading frame relative to the upstream ATG sequence in the vector (25). The DNA fragment containing the entire $C Y R I$ gene was obtained by introducing an EcoRI site directly in front of the ATG initiation codon by in vitro mutagenesis (26). YCpLe, which has the $L E U 2, A R S 1$, and CEN4 sequences, was prepared from YEp13 and YCp19 (26). The GAP promoter was prepared as the 1.1-kb 5'-flanking region of the glyceraldehyde-3-phosphate dehydrogenase gene (6). The promoter and truncated CYRI genes shown in Fig. 1 were inserted into YIpLe, which has the LEU2 gene from YEp13 and pBR322 sequences (26). The plasmids were designated YIpLe GAPCYR1, YIpLeGAPCYR1-BglII, and YIpLeGAPCYR1ScaI (a). Each plasmid was integrated into each transformant as a single copy, judging from the results of genetic analysis and Southern hybridization experiments.

Media and genetical manipulations. Yeast cells were grown in liquid medium at 25 or $30^{\circ} \mathrm{C}$. Minimal medium contained $6.9 \mathrm{~g}$ of yeast nitrogen base without amino acids (Difco Laboratories, Detroit, Mich.) and $20 \mathrm{~g}$ of glucose in 1 liter of distilled water. Complete medium (YPGlu) contained $10 \mathrm{~g}$ of yeast extract, $20 \mathrm{~g}$ of peptone, and $20 \mathrm{~g}$ of glucose in 1 liter of distilled water. Nitrogen-free medium contained $20 \mathrm{~g}$ of 
TABLE 1. List of yeast strains used

\begin{tabular}{|c|c|c|}
\hline Strain & Genotype & Source or reference \\
\hline IU-1B & a leu2 his3 ura3 trpl & Segregant from RA1 (26) \\
\hline IU-4C & a leu2 his3 ura3 trp1 & Segregant from RA1 (26) \\
\hline RA1 & a/ $\alpha$ leu2/leu2 his3/his3 ura3/ura3 trpl/trpl ras $1:: H I S 3 /$ ras $2:: U R A 3$ & 23 \\
\hline R158-1 & a/a leu2/leu2 his $3 /$ his 3 ura3/ura3 trp1/trp1 ras $1:: H I S 3 /$ ras $2:: U R A 3$ cyrl::TRP1 & Transformant of RA1 (26) \\
\hline R177 & a/ $\alpha$ leu2/leu2 his $3 /$ his 3 ura3/ura3 trpl/trpl rasl::HIS3 cyrl::TRPI & Transformant of R158-1 (26) \\
\hline R177-1B & $\alpha$ leu2 his3 ura3 trp1 cyr1::TRPI(YIpLeGAPCYR1-BglII) & Segregant from R177 (26) \\
\hline R181 & Diploid (R177-1B $\times$ T12-1B) & This work \\
\hline R182 & Diploid (IU-1B $\times$ IU-4C) & This work \\
\hline T12-1B & a leu2 his3 ura3 trpl cyrl::TRPl(YIpLeGAPCYR1-BglII) & Segregant from R177 \\
\hline IU4-1B & Isogenic with IU-1B except MATa & This work \\
\hline IU14 & Diploid (IU-1B × IU4-1B) & This work \\
\hline IU14-1 & a/a leu2/leu2 his3/his3 ura3/ura3 trpl/trpl cyrl::TRPI & Transformant of IU14 (26) \\
\hline IU24 & $\mathrm{a} / \alpha$ leu2/leu2 his $3 /$ his3 ura3/ura3 trp1/trp1 cyrl::TRP1(YIpLeGAPCYR1) & Transformant of IU14-1 \\
\hline IU24-1C & a leu2 his3 ura3 trpl cyrl::TRP1(YIpGAPCYR1) & Segregant from IU24 \\
\hline IU24-1D & $\alpha$ leu2 his3 ura3 trpl cyrl::TRPI & Segregant from IU24 \\
\hline IU47 & Diploid (IU24-1C × IU24-1D) & This work \\
\hline IU50 & a/a leu2/leu2 his3/his3 ura3/ura3 trpl/trp1 cyrl::TRPI(YILeGAPCYR1-BglII) & Transformant of IU14-1 \\
\hline IU50-1D & a leu2 his3 ura3 trpl cyrl::TRPI(YIpLeGAPCYR1-BglII) & Segregant from IU50 \\
\hline IU50-2C & a leu2 his3 ura3 trp1 cyr1::TRP1(YIPLeGAPCYR1-BglII) & Segregant from IU50 \\
\hline IU53 & Diploid (IU50-1B $\times$ IU50-2C) & This work \\
\hline IU54 & Diploid (IU50-B × IU-B) & This work \\
\hline IU70 & a/ $\alpha$ leu2/leu2 his3/his3 ura3/ura3 trpl/trpl cyrl::TRPI[YIpLeGAPCYR1-ScaI(a)] & Transformant of IU14-1 \\
\hline IU70-5B & a leu2 his3 ura3 trpl cyrl::TRP1[YIpLeGAPCYR1-ScaI(a)] & Segregant from IU70 \\
\hline IU70-7D & a leu2 his3 ura3 trpl cyrl::TRPI[YIpLeGAPCYR1-ScaI(1)] & Segregant from IU70 \\
\hline IU76 & Diploid (IU70-5B $\times$ IU70-7d) & This work \\
\hline
\end{tabular}

glucose and $1.7 \mathrm{~g}$ of yeast nitrogen base without amino acids and ammonium sulfate (Difco) in 1 liter of distilled water. Sporulation medium (SP) contained $10 \mathrm{~g}$ of sodium acetate in 1 liter of distilled water. The methods used for genetic analyses were described by Sherman et al. (21).

cAMP level. Intracellular cAMP levels were determined by the method of Gilman (5).

Indirect immunofluorescence observation. Indirect immunofluorescence observation was carried out by the method of Kilmartin and Adams (11). Yeast cells were fixed with 3.5\% formaldehyde at 25 or $37^{\circ} \mathrm{C}$, and the cell wall was removed with Zymolyase 20T (Kirin Brewery Co., Ltd., Takasaki, Japan). These cells were further treated with $0.1 \%$ Triton X-100 and fixed on a cover slip. These slips were then treated with a bovine serum albumin solution containing $3 \%$ bovine serum albumin, $1.2 \mathrm{M}$ sorbitol, $0.15 \mathrm{M} \mathrm{NaCl}$, and 50 $\mathrm{mM}$ phosphate buffer ( $\mathrm{pH}$ 6.8), with antitubulin antibody (Sera Laboratory, Sussex, England), and with fluorescein isothiocyanate (FITC)-labeled anti-rat immunoglobulin anti-

A

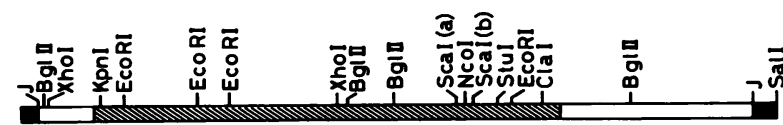

B

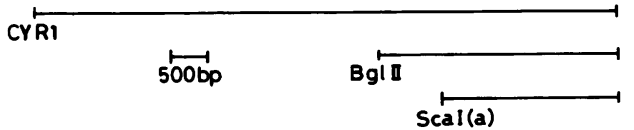

FIG. 1. Structure of the yeast $C Y R 1$ gene. (A) Restriction map of the yeast DNA insert of plasmid pCEY710. The coding sequence for the CYRI gene is indicated by the hatched bar, while the black boxes represent the vector YRp7 DNA (13). Representative restriction sites of the $C Y R I$ gene are shown. J, Junction between insert DNA and a BamHI cleavage site of the vector YRp7 DNA. (B) DNA fragment used for the construction of the plasmids carrying the entire or truncated CYRI gene. The bars represent the DNA fragments used for the construction of the plasmids. body (Cappel Co., Malvern, Pa.). The cells were viewed with a $100 \times$ objective on a Nikon microscope equipped for fluorescence microscopy, using blue excitation for FITClabeled staining.

Electron microscopy. Yeast cells were fixed in $3 \%$ glutaraldehyde in $0.1 \mathrm{M}$ phosphate buffer $(\mathrm{pH} \mathrm{7.0)}$ for $2 \mathrm{~h}$. Fixation of culture was preceded by treatment for $10 \mathrm{~min}$ at $25^{\circ} \mathrm{C}$ with $0.1 \mathrm{M} \beta$-mercaptoethanol in $0.02 \mathrm{M}$ EDTA and 0.2 M Tris hydrochloride buffer ( $\mathrm{pH} 8.0)$ to facilitate later removal of walls. After glutaraldehyde fixation, cell walls were removed by incubation of the washed cells with $\mathrm{Zy}$ molyase 20T $(0.1 \mathrm{mg} / \mathrm{ml})$ in $0.2 \mathrm{M}$ phosphate buffer $(\mathrm{pH} \mathrm{7.0)}$. Cells were subsequently postfixed for $60 \mathrm{~min}$ at $25^{\circ} \mathrm{C}$ in $2 \%$ osmium tetraoxide in $0.1 \mathrm{M}$ phosphate buffer $(\mathrm{pH} 7.0$ ), washed well with distilled water, treated for $60 \mathrm{~min}$ at $20^{\circ} \mathrm{C}$ with $2 \%$ uranyl acetate, dehydrated, and embedded in Spurr resin. Blocks were serially sectioned on a Sorvall MT-2 ultramicrotome (Du Pont Co., Wilmington, Del.) into 80nm-thick sections; the ribbons were picked up on the Formvar films on oval single-hole grids ( 1 by $2 \mathrm{~nm}$ ), stained successively with uranyl acetate and lead citrate, and viewed in a JEOL $200 \mathrm{CX}$ electron microscope (JEOL, Akishima, Japan) at $100 \mathrm{kV}$.

\section{RESULTS}

Growth and sporulation of diploid cryl cells carrying truncated $C Y R 1$ genes. The restriction map and complete DNA sequence of $C Y R I$ were described by Kataoka et al. (10). A simple restriction map of $C Y R I$ is presented in Fig. 1. It has been suggested that the catalytic domain of adenylate cyclase is encoded by the $1.3-\mathrm{kb}$ region of the open reading frame of the $C Y R I$ gene encoding the C-terminal domain of adenylate cyclase (10), and the domain encoded by the $0.8-\mathrm{kb}$ region adjacent to the catalytic domain is associated with the regulatory function of the $R A S$ products (26). To examine the sporulation of the diploid cryl cells carrying a truncated $C Y R I$ gene, we constructed yeast YIp-type plas- 
TABLE 2. Growth arrest and sporulation of diploid cells carrying the entire region or a fragment of the CYRI gene

\begin{tabular}{|c|c|c|c|c|c|}
\hline \multirow[b]{2}{*}{ Strain } & \multirow[b]{2}{*}{ Relevant genotype } & \multicolumn{2}{|c|}{$\%$ Unbudded cells ${ }^{a}$} & \multicolumn{2}{|c|}{ Sporulation ${ }^{b}$} \\
\hline & & $\begin{array}{l}\text { YPGlu } \\
\text { medium }\end{array}$ & $\begin{array}{c}\mathrm{SP} \\
\text { medium }\end{array}$ & $\begin{array}{l}\text { Total no. } \\
\text { of asci }\end{array}$ & $\begin{array}{l}\% \text { of asc } \\
\text { with bud }\end{array}$ \\
\hline R182 & $+1+$ & 91 & 89 & 67 & 0 \\
\hline R181 & $\operatorname{cyrl(YIpLeGAPCYR1-BgIII)/cyrl(YIpLeGAPCYR1-BglII)~}$ & 85 & 11 & 32 & 76 \\
\hline IU14 & 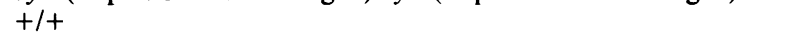 & 92 & 93 & 72 & $\mathbf{0}$ \\
\hline IU47 & cyrl(YIpLeGAPCYR1)/cyrl(YIpLeGAPCYR1) & 95 & 94 & 69 & $\mathbf{0}$ \\
\hline IUS3 & cyrl(YIpLeGAPCYR1-BglII)/cyrl(YIpLeGAPCYR1-BglII) & 86 & 9 & 53 & 72 \\
\hline IU54 & cyrl(YIpLeGAPCYR1-BglII)/+ & 91 & 86 & 71 & 12 \\
\hline IU76 & cyr1[YIpLeGAPCYR1-ScaI(a)]/cyr1[YIpLeGAPCYR1-ScaI(a)] & 42 & 17 & 11 & 74 \\
\hline
\end{tabular}

${ }^{a}$ Diploid cells were incubated in YPGlu or SP medium for $48 \mathrm{~h}$, and the number of unbudded cells was counted.

$b$ Diploid cells were incubated in SP medium for $48 \mathrm{~h}$ and the number of sporulating cells (asci) was counted. Among the sporulating cells, the percentage of sporulating cells with one or more buds was calculated.

mids carrying a highly expressed GAP promoter and a fragment of the $C Y R 1$ coding region. The $C Y R 1$ diploid cells were growth arrested and accumulated unbudded cells (about $90 \%$ of total) after incubation in SP medium as well as in YPGlu medium or in nitrogen-free medium (Table 2, Fig. 2). These cells incubated in SP medium were able to sporulate and produced normal asci (Table 2). The cyrl diploid cells, carrying the entire coding region of $C Y R I$, were growth arrested after incubation in YPGlu or SP medium and sporulated normally like the $C Y R I$ diploid cells (Table 2). The cyrl diploid cells (R181 and IU53) carrying the BglII fragment of $C Y R I$ encoding the C-terminal domain of adenylate cyclase were growth arrested and accumulated unbudded cells (more than $80 \%$ of total) after incubation in YPGlu medium or nitrogen-free medium (Fig. 2), but accu- mulated few unbudded cells (about $10 \%$ of total) after incubation in SP medium (Table 2, Fig. 2). These cells continued budding after incubation in SP medium and produced asci which were mostly abnormal, bearing one to several buds (Table 2, Fig. 2). The time course of sporulation for the cyrl diploid cells carrying the $B g I I I$ fragment of $C Y R I$ is shown in Fig. 3. The number of budded cells increased and reached the maximal level $(90 \%)$ after $8 \mathrm{~h}$. The number of cells bearing one or more buds began to increase after $5 \mathrm{~h}$ and reached the maximal level $(90 \%)$ after $10 \mathrm{~h}$ (Fig. 3). Sporulation was observed after $24 \mathrm{~h}$, and most asci bore abnormal buds (Fig. 3).

The cyrl diploid cells carrying the ScaI(a) fragment of $C Y R I$ were not arrested in either YPGlu or SP medium like the $C Y R I$ diploid cells and produced few asci (Table 2). The
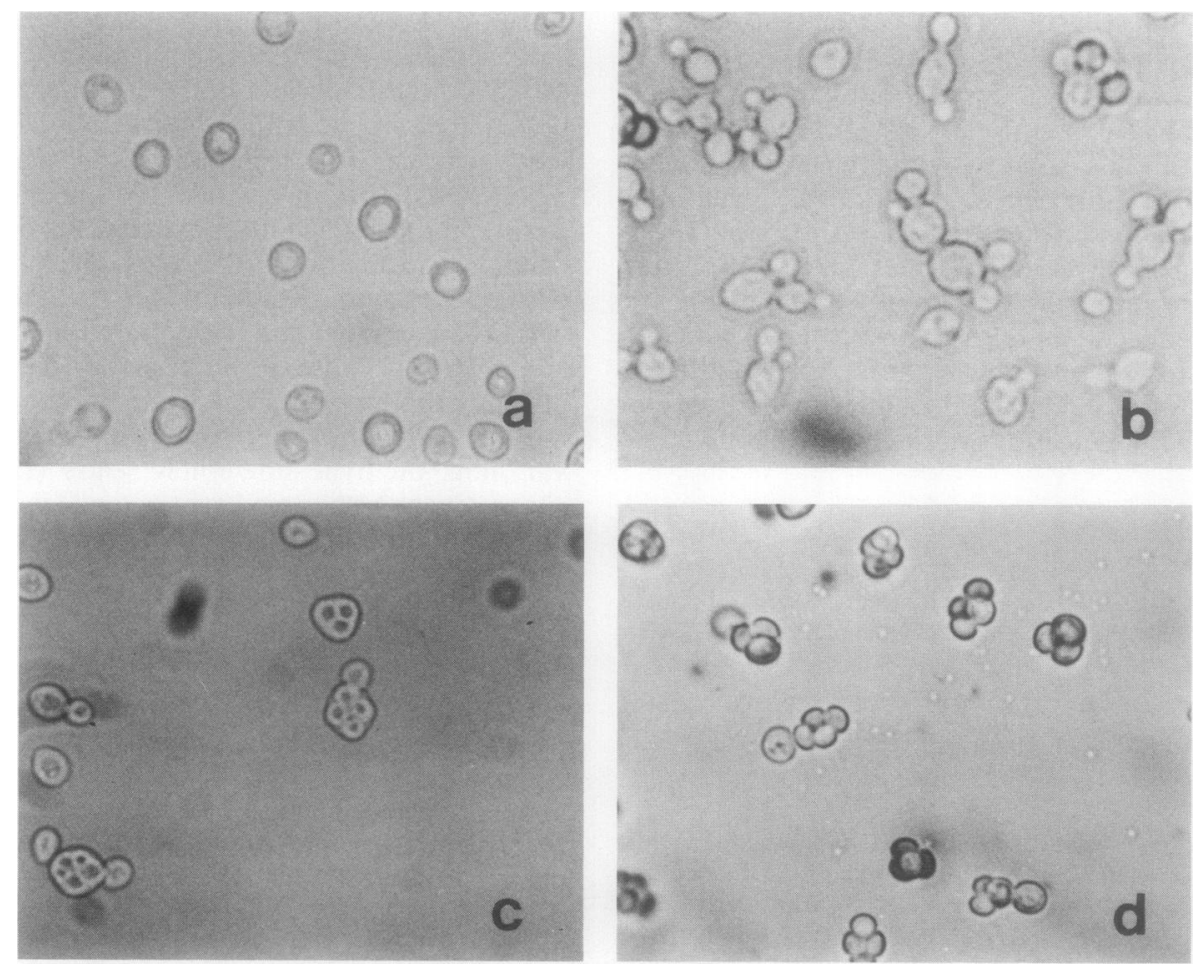

FIG. 2. Phenotype of strain IU53, cyrl diploid cells carrying the BglII fragment of $C Y R 1$. A culture of strain IU53 grown in YPGlu medium to log phase was separated into two parts. One part was transferred to the nitrogen-free medium, and the cells were observed after $24 \mathrm{~h}$ (a). The other part was transferred to SP medium, and the cells were observed after $7 \mathrm{~h}$ (b) and $24 \mathrm{~h}$ (c). The CYRI diploid cells (IU14) were transferred to SP medium and observed after $24 \mathrm{~h}(\mathrm{~d})$. 


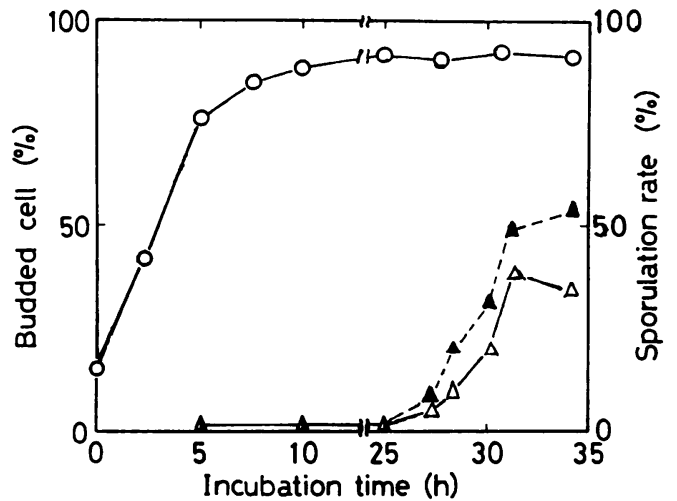

FIG. 3. Time course of sporulation of the cyrl diploid cells carrying the BglII fragment of $C Y R I$ (IU53). Diploid cells of strain IU53 were grown in YPGlu medium for $24 \mathrm{~h}$ and transferred to SP medium. At the indicated time, the percentage of cells forming one or more buds $(O)$ was determined. The percentages of cells containing spores $(\Delta)$ and of budded cells containing spores $(\Delta)$ were also determined.

heterozygous diploid cells YIPleGAPCYR1-BglII (+/cyrl) were arrested like the $C Y R I$ diploid cells in both YPGlu and SP media and produced many asci (Table 2). The results indicate that the inability to grow and sporulate in SP medium is a recessive character.

Meiosis in the cyrl diploid cells carrying the truncated $C Y R I$ genes. Diploid cells were incubated in SP medium at $30^{\circ} \mathrm{C}$ for $10 \mathrm{~h}$ and stained with antitubulin and FITC-labeled antibodies. The $C Y R I$ diploid cells usually had one spindle during the first meiotic division and two spindles during the second meiotic division (Fig. 4). The cyrl diploid cells carrying the $B g l$ II fragment of $C Y R I$ frequently had abnormal spindles which were larger in some cases, showed abnormal distribution, and were frequently observed in buds of the ascus cells (Fig. 4). The frequency of appearance of abnormal spindles was significantly higher in the cyrl diploid cells carrying the $B g l I I$ fragment of $C Y R I$ than in the $C Y R I$ diploid cells, as indicated in Table 3 .

The diploid cells were fixed, thin-sectioned, and observed under the electron microscope. In many cyrl diploid cells
TABLE 3. Appearance of various types of spindles during incubation of $C Y R I$ diploid cells (IU14) and cyrl diploid cells carrying the BglII fragment of $C Y R I$ (IU53) in SP medium

\begin{tabular}{lcrrrrrr}
\hline \multirow{2}{*}{ Strain } & $\begin{array}{c}\text { Incubation } \\
\text { time }^{a}(\mathrm{~h})\end{array}$ & \multicolumn{6}{c}{ \% of cells with spindle type ${ }^{b}:$} \\
\cline { 3 - 8 } & & I & II & III & IV & V & VI \\
\hline IU14 & 8 & 82 & 8 & 6 & 0 & 0 & 4 \\
& 10 & 28 & 44 & 21 & 0 & 0 & 7 \\
& 12 & 27 & 19 & 46 & 0 & 0 & 8 \\
IU53 & 8 & 21 & 0 & 0 & 31 & 33 & 15 \\
& 10 & 17 & 3 & 3 & 19 & 49 & 9 \\
& 12 & 16 & 3 & 2 & 11 & 58 & 10 \\
\hline
\end{tabular}

${ }^{a}$ The diploid cells were incubated in SP medium at $25^{\circ} \mathrm{C}$

${ }^{b}$ The cells were fixed, stained with antibody to tubulin, and observed by fluorescent microscopy. The types of spindles were determined as shown in Fig. 4. I, One spindlelike spot (Fig. 4a); II, two spindlelike spots (Fig. 4b); III, two spindlelike bars (Fig. 4c); IV, one thick spindle in the mother cell and one spindlelike spot in the daughter cell (Fig. 4d); V, one spindlelike bar in the mother cell and in the daughter cell (Fig. 4e and f); VI, other spindlelike structures. All values are indicated as percentage of 600 cells observed.

carrying the $B g l I I$ fragment of $C Y R 1$, fragments of spindles which were not associated with the spindle pole bodies were observed in the serial sections of a cell (Fig. 5). In some cases the spindle fibers were thicker than those of $C Y R I$ cells (Fig. 6), and thick bundles of microtubules were frequently observed in the cytoplasm (Fig. 6), although very thin microtubules were rarely observed in the cytoplasm of CYRI cells. These results suggest that the assembly of tubulin and/or microtubule-associated proteins may be disordered in cyrl diploid cells carrying the BglII fragment of CYRI.

cAMP levels observed during sporulation. The $C Y R I$ diploid cells and cyrl diploid cells carrying the $B g l$ II fragment of $C Y R I$ produced constant levels of cAMP during growth at $25^{\circ} \mathrm{C}$ in YPGlu medium. The cAMP levels of $C Y R I$ diploid cells decreased to the minimum values after transfer to SP medium and then increased (Fig. 7). The peak of cAMP level was observed after $10 \mathrm{~h}$ of incubation in SP medium. The cAMP level of the cyrl diploid cells carrying the BgIII fragment of $C Y R I$ decreased to about half of that produced in YPGlu medium. No significant increase in the cAMP level was observed in the cyrl diploid cells carrying the $B g l I I$ fragment of $C Y R I$ incubated in SP medium (Fig. 7). It is
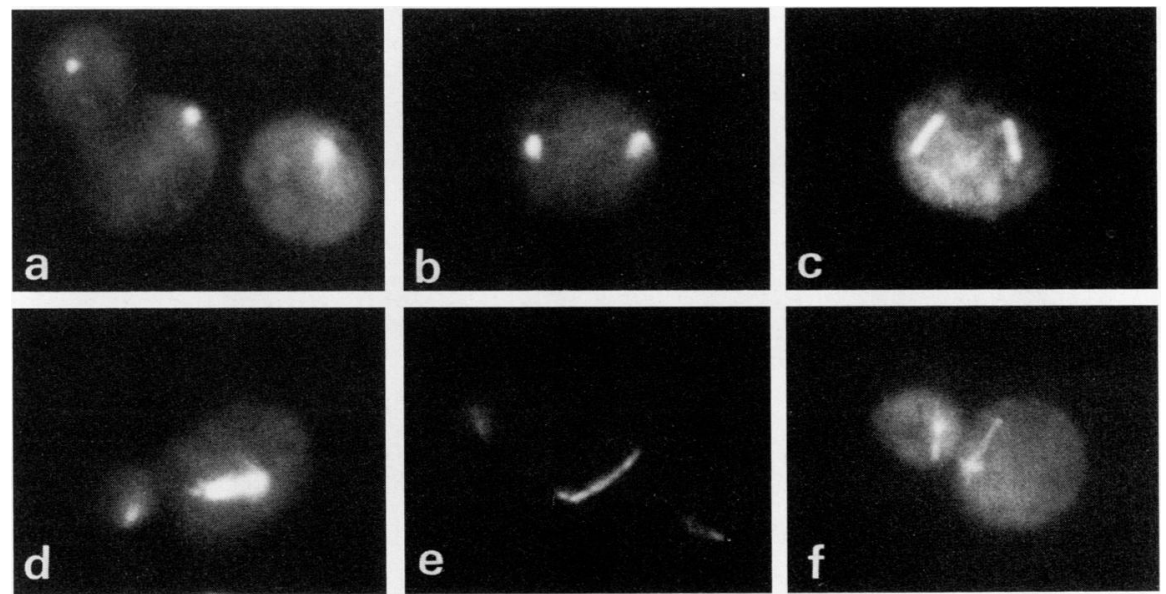

FIG. 4. Observation of spindles in $C Y R I$ diploid cells (R182) and cyrl diploid cells carrying the $B g l$ II fragment of $C Y R$ (R181). The R182 cells were incubated in SP medium at $25^{\circ} \mathrm{C}$ for $0 \mathrm{~h}$ (a), $8 \mathrm{~h}$ (b), and $19 \mathrm{~h}$ (c). The R181 cells were incubated in SP medium at $25^{\circ} \mathrm{C}$ for $8 \mathrm{~h}(\mathrm{~d})$, $10 \mathrm{~h}(\mathrm{e})$, and $12 \mathrm{~h}(\mathrm{f})$. These cells were fixed and stained with antibody to tubulin. 

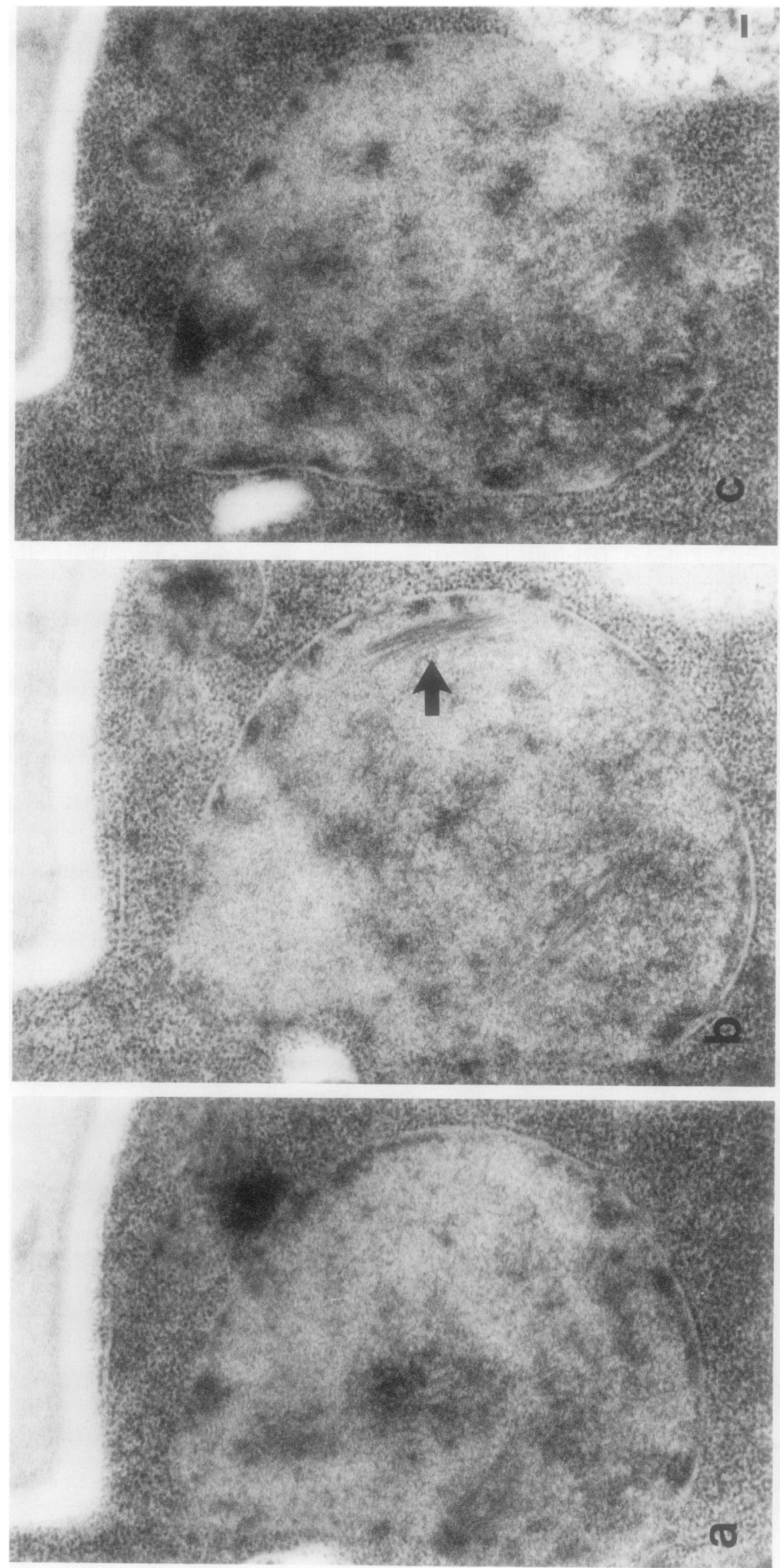

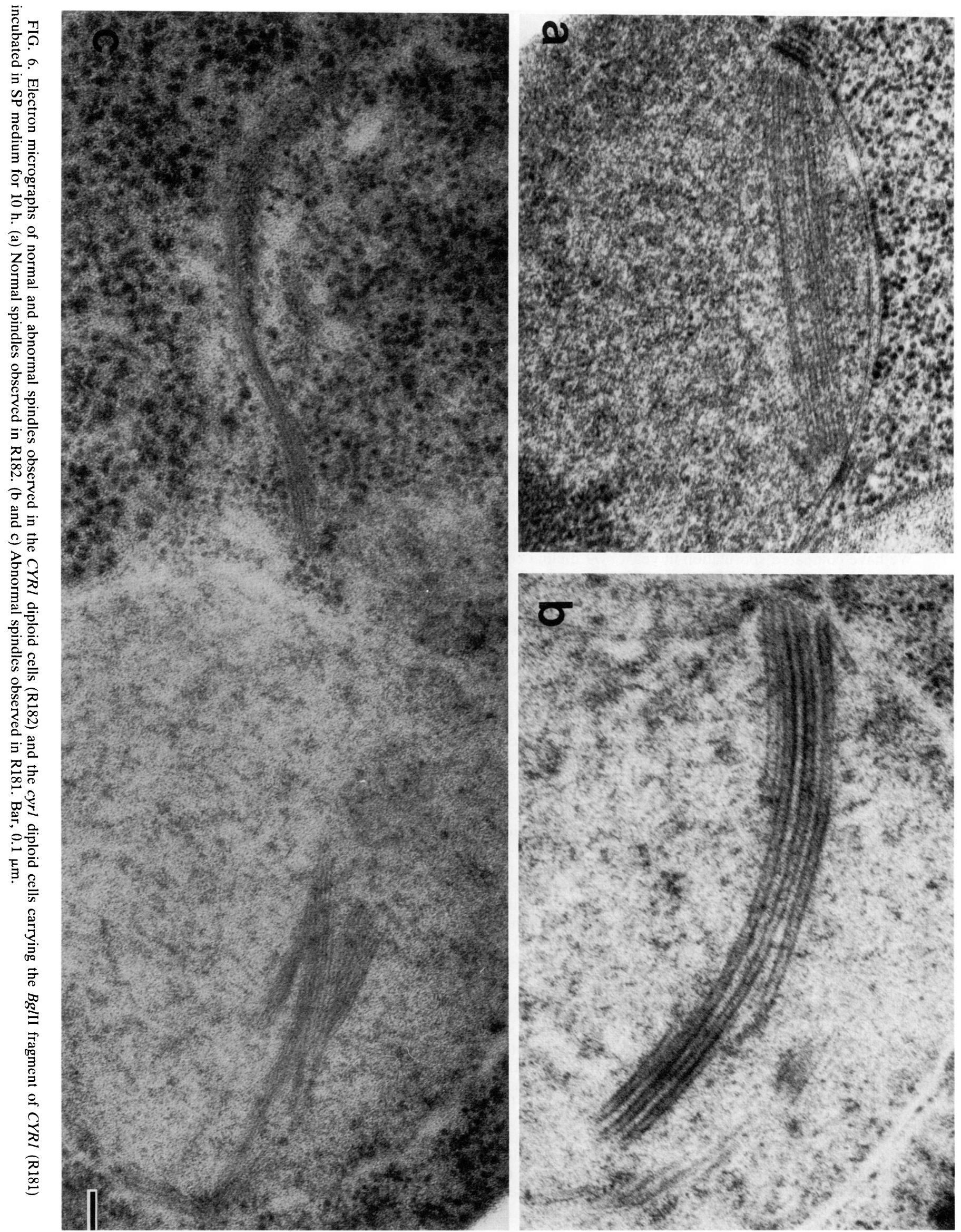


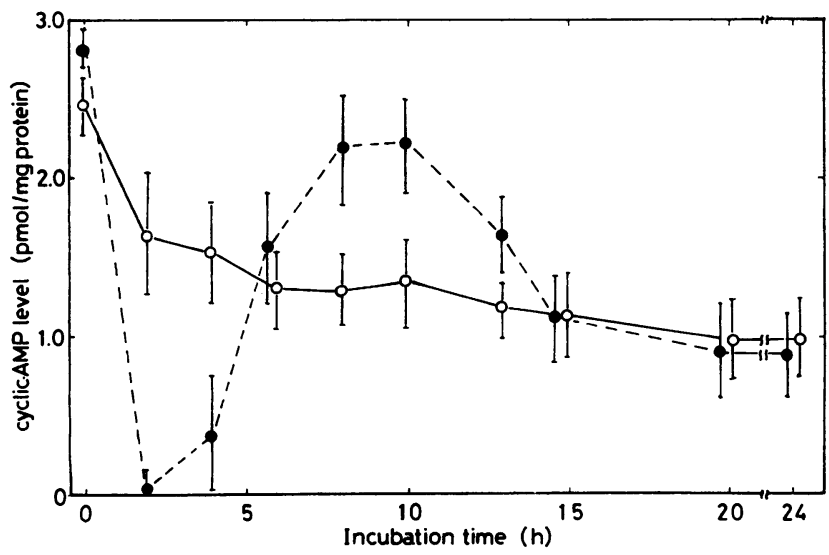

FIG. 7. cAMP levels during sporulation of the $C Y R I$ diploid cells $(I U 14,0)$ and cyrl diploid cells carrying the BglII fragment of $C Y R I$ (IU53, O). IU14 and IU53 cells were cultivated first in YPGlu medium at $25^{\circ} \mathrm{C}$ for $15 \mathrm{~h}$ and then in SP medium. The cells were harvested at various times, and cAMP levels were measured. Error bars indicate standard error of the mean.

pointed out from this result that the drastic decrease of cAMP level in SP medium was not observed in the cyrl diploid cell carrying the $B g l I I$ fragment of $C Y R I$, and many cells continued to produce buds forming spores.

\section{DISCUSSION}

We have compared sporulation in yeast cyrl diploid cells carrying the truncated $C Y R I$ genes. The product of the 2.1-kb region of $C Y R I$ which encodes the C-terminal domain of adenylate cyclase showed guanine nucleotide-dependent adenylate cyclase activity and produced a large amount of cAMP in the presence of $R A S$ genes $(25,26)$. cyrl $R A S I$ $R A S 2$ cells carrying the $1.3-\mathrm{kb}$ region rencoding the $\mathrm{C}$ terminal domain of adeylate cyclase were unable to respond to environmental signals for growth, such as sulfur starvation and temperature shift, but the cyrl cells carrying the 2.1-kb $B g$ III fragment and at least one $R A S$ gene were able to respond to these signals. The environmental signals for growth may be transferred to adenylate cyclase through the $R A S$ products (26).

Yeast cyrl diploid cells carrying the entire coding region of $C Y R 1$ were growth arrested in the sporulation medium and produced normal asci, but those carrying the $2.1-\mathrm{kb}$ $B g I I I$ region or $1.3-\mathrm{kb} S c a I(a)$ region of $C Y R 1$ were not growth arrested and produced asci which possessed one or more buds. In these cells the number of abnormally budded cells increased after incubation in the sporulation medium. It was evident from these data that the 4-kb region of $C Y R I$ which encodes the $\mathrm{N}$-terminal domain of adenylate cyclase is responsible for normal sporulation.

The cAMP level of the $C Y R I$ diploid cells fell rapidly in the sporulation medium (24), and the cells arrested at the G1 phase of the cell cycle and initiated sporulation. The cAMP level of the cyrl diploid cells carrying the $B g l \mathrm{II}$ fragment of $C Y R I$ did not decrease to the $C Y R I$ level in the sporulation medium, and most cells were not arrested at the G1 phase and continued budding even in the sporulation medium. The cAMP contents of the cyrl diploid cells carrying the $B g / I I$ fragment of $C Y R I$ kept a constant level in the sporulation medium, in contrast to those cells carrying the entire coding region of $C Y R I$. Growth of the cyrl diploid cells carrying the entire coding region of $C Y R 1$ was arrested at the $\mathrm{G} 1$ phase in the sporulation medium as well as in complete medium or nitrogen-free medium. On the other hand, growth of the cyrl diploid cells carrying the BgIII fragment of $C Y R I$ was arrested in complete medium or in nitrogen-free medium, but not in the sporulation medium. This may imply that the diploid cells lacking the 4-kb region of $C Y R I$ encoding the $\mathrm{N}$-terminal domain of adenylate cyclase were unable to respond normally to the environmental signals for sporulation. The data indicate a possibility that the $\mathrm{N}$-terminal region of $C Y R I$ product interacts with a factor which negatively controls adenylate cyclase activity in response to an environmental signal for sporulation. The factor may be similar to the inhibitory $G$ proteins found in mammalian cells $(8,9,20)$.

Abnormality of the cyrl diploid cells carrying the $B g I I I$ fragment of CYRI was observed in the structure and distribution of spindles. One or more fragments of spindles free from the spindle pole bodies were frequently found in nuclei and cytoplasm. If tubulin assembly is influenced by protein phosphorylation, as observed in mammalian cells $(2,12,22)$, the abnormality of spindles may be caused by abnormal cAMP-dependent phosphorylation of tubulin and/or microtubule-associated proteins during the meiotic processes.

\section{LITERATURE CITED}

1. Casperson, G. F., N. Walker, and H. R. Bourne. 1985. Isolation of the encoding adenylate cyclase in Saccharomyces cerevisiae. Proc. Natl. Acad. Sci. USA 82:5060-5063.

2. Cleveland, D. W., S. Hwo, and M. W. Kirschner. 1977. Physical and chemical properties of purified tau factor and the role of tau in microtubule assembly. J. Mol. Biol. 116:227-247.

3. Defeo-Jones, D., E. M. Scolnick, R. Koller, and R. Dhar. 1983. ras-Related gene sequences identified and isolated from Saccharomyces cerevisiae. Nature (London) 306:707-709.

4. Dhar, R., A. Nieto, R. Koller, D. Defeo-Jones, and E. M. Scolnick. 1984. Nucleotide sequence of two ras $^{\mathrm{H}}$-related genes isolated from the yeast Saccharomyces cerevisiae. Nucleic Acids Res. 12:3611-3618.

5. Gilman, A. G. 1970. A protein binding assay for adenosine 3',5'-cyclic monophosphate. Proc. Natl. Acad. Sci. USA 67: 305-312.

6. Holland, J. P., and M. J. Holland. 1979. The primary structure of a glyceraldehyde-3-phosphate dehydrogenase gene from Saccharomyces cerevisiae. J. Biol. Chem. 254:9839-9845.

7. Jensen, R. E., and I. Herskowitz. 1984. Directionality and regulation of cassette subtitution in yeast. Cold Spring Harbor Symp. Quant. Biol. 49:97-104.

8. Katada, T., and M. Ui. 1982. Direct modification of the membrane adenylate cyclase system by islet-activating protein due to ADP-ribosylation of a membrane protein. Proc. Natl. Acad. Sci. USA 79:3129-3133.

9. Katada, T., and M. Ui. 1982. ADP-ribosylation of the specific membrane protein of $\mathrm{C} 6$ cells by islet-activating protein associated with modification of adenylate cyclase activity. J. Biol. Chem. 257:7210-7216.

10. Kataoka, T., D. Broek, and M. Wigler. 1985. DNA sequence and characterization of the $S$. cerevisiae gene encoding adenylate cyclase. Cell 43:493-505.

11. Kilmartin, J. V., and A. E. M. Adams. 1984. Structural rearrangements of tubulin and actin during the cell cycle of the yeast Saccharomyces. J. Cell. Biol. 98:922-933.

12. Lohmann, S. M., P. DeCamilli, I. Einig, and U. Walter. 1984. High affinity binding of the regulatory subunit $\left(R_{I I}\right)$ of cAMPdependent protein kinase to microtubule-associated and other cellular proteins. Proc. Natl. Acad. Sci. USA 81:6723-6727.

13. Masson, P., J. M. Jacquemin, and M. Culot. 1984. Molecular cloning of the $t s m O 185$ gene responsible for adenylate cyclase activity in Saccharomyces cerevisiae. Ann. Microbiol. (Inst. Pasteur) 135:343-351.

14. Masson, P., J. Lenzen, J. M. Jacquemin, and A. Danchin. 1986. Yeast adenylate cyclase catalytic domain is carboxy terminal. 
Curr. Genet. 10:343-352.

15. Matsumoto, K., I. Uno, and T. Ishikawa. 1983. Control of cell division in Saccharomyces cerevisiae mutants defective in adenylate cyclase and cAMP-dependent protein kinase. Exp. Cell Res. 146:151-161.

16. Matsumoto, K., I. Uno, and T. Ishikawa. 1983. Initiation of meiosis in yeast mutants defective in adenylate cyclase and cyclic AMP-dependent protein kinase. Cell 32:417-423.

17. Matsumoto, K., I. Uno, and T. Ishikawa. 1985. Genetic analysis of the role of cAMP in yeast. Yeast 1:15-24.

18. Matsumoto, K., I. Uno, Y. Oshima, and T. Ishikawa. 1982. Isolation and characterization of yeast mutants deficient in adenylate cyclase and cAMP-dependent protein kinase. Proc. Natl. Acad. Sci. USA 79:2355-2359.

19. Powers, S., T. Kataoka, O. Fasano, M. Goldfarb, J. Strathern, J. Broach, and M. Wigler. 1984. Genes in S. cerevisiae encoding proteins with domains homologous to the mammalian ras proteins. Cell 36:607-612.

20. Rodbell, M. 1980. The role of hormone receptors and GTPregulatory proteins in membrane transduction. Nature (London) 284:17-22.

21. Sherman, F., G. R. Fink, and J. B. Hicks. 1986. Laboratory course mannual for methods in yeast genetics. Cold Spring
Harbor Laboratory, Cold Spring Harbor, N.Y.

22. Sloboda, R. D., S. A. Rudolph, J. L. Rosenbaum, and $\mathbf{P}$. Greengard. 1975. Cyclic AMP-dependent endogenous phosphorylation of a microtubule-associated protein. Proc. Natl. Acad. Sci. USA 72:177-181.

23. Toda, T., I. Uno, T. Ishikawa, S. Powers, T. Kataoka, D. Broek, S. Cameron, J. Broach, K. Matsumoto, and M. Wigler. 1985. In yeast, $R A S$ proteins are controlling elements of adenylate cyclase. Cell 40:27-36.

24. Uno, I., K. Matsumoto, A. Hirata, and T. Ishikawa. 1985. Outer plaque assembly and spore encapsulation are defective during sporulation of adenylate cyclase-deficient mutants of Saccharomyces cerevisiae. J. Cell Biol. 100:1854-11862.

25. Uno, I., H. Mitsuzawa, K. Matsumoto, K. Tanaka, T. Oshima, and T. Ishikawa. 1985. Reconstitution of the GTP-dependent adenylate cyclase from products of the yeast CYRI and RAS2 genes in Escherichia coli. Proc. Natl. Acad. Sci. USA 82: 7855-7859.

26. Uno, I., H. Mitsuzawa, K. Tanaka, T. Oshima, and T. Ishikawa. 1987. Identification of the domain of Saccharomyces cerevisiae adenylate cyclase associated with the regulatory function of $R A S$ products. Mol. Gen. Genet. 210:187-194. 